\title{
O cerco à indústria farmacêutica nos Estados Unidos
}

\author{
Mônica Teixeira
}

Não apenas na Europa a indústria farmacêutica enfrenta críticas e oposição, como esta seção tem procurado acompanhar e documentar. Nos Estados Unidos, o governo federal e parte dos governos dos Estados movimentam-se para evitar que os pagamentos realizados aos laboratórios no âmbito de programas públicos de prestação de serviços de saúde continuem crescendo. Apenas o programa Medicaid, que atende os 40 milhões de norteamericanos mais pobres, e cujos custos são divididos entre estados e União, consumiu no ano passado 250 bilhões de dólares, $13 \%$ a mais que em 2001 - incremento que o transforma no item de crescimento mais rápido dentro dos orçamentos estagnados ou declinantes de muitos estados norte-americanos. $\mathrm{O}$ gasto com medicamentos que exigem receita médica é parte expressiva destes custos. No Estado de Nova Iorque, por exemplo, representa 7,5\% de toda a despesa do Medicaid, ou 2,4 bilhões de dólares - valor que cresceu 75\% entre 1996 e 2001. Para o conjunto dos Estados Unidos, os gastos com medicamentos do Medicaid, somados àqueles realizados pelo Medicare, - que atende os cidadãos idosos - ultrapassam 30 bilhões de dólares anuais. 
A escalada de custos com medicamentos explica-se pelos preços crescentes praticados pela indústria - que, segundo ela, resulta dos altos investimentos realizados em pesquisa e desenvolvimento de novas drogas -, mas também por práticas de marketing e de vendas utilizadas pelas companhias farmacêuticas e apontadas como ilegais pelos procuradores do Ministério da Justiça. Durante o ano fiscal encerrado a 30 de setembro de 2002, acordos obtidos pelo escritório do procurador dos Estados Unidos do distrito de Massachusetts, resultado de ações levadas aos tribunais, obrigaram fabricantes de medicamentos a pagar 900 milhões de dólares em multas criminais e civis. A unidade de Combate a Fraudes em Serviços de Saúde de Massachusetts é a mais ativa dos Estados Unidos no setor, o que se justifica pelo fato de a maior parte das Big Pharma estarem sediadas em Boston, capital do Estado.

Além das medidas dos estados e do governo federal para cortar gastos, e da perseguição encetada pelos procuradores, a indústria passa agora a enfrentar ações interpostas por grupos muito organizados de advogados, representando pessoas que alegam terem tido a saúde prejudicada pela ingestão de determinados medicamentos. Estes consórcios de advogados investem milhões de dólares na preparação de casos contra os fabricantes. Buscam clientes em todos os Estados, trocam informações entre si, escolhem juízes e tribunais que poderão decidir favoravelmente, usam as condenações para levar as companhias a aceitarem acordos bilionários. Os casos relatados neste artigo - das medidas restritivas dos governos, das práticas reconhecidas como ilegais pelos tribunais, e das ações em torno de efeitos adversos causados por drogas comercializadas no país resultam do acompanhamento do noticiário produzido pelo jornal New York Times durante os cinco primeiros meses de 2003.

\section{Os Estados contra a Indústria nos tribunais}

O caso do Estado de Nova Iorque contra a Pharmacia Corporation exemplifica de que maneira as práticas de marketing e vendas das companhias farmacêuticas aumentam os custos dos programas de saúde pública norteamericanos. Em sua representação perante a Suprema Corte do Estado, o procurador geral acusa a empresa de "fazer deturpações fraudulentas e enganosas que escondem o verdadeiro preço médio de venda por atacado de suas drogas”. Este "preço médio de venda no atacado" (average wholesale price) é declarado pelas próprias companhias e nele se baseia o valor dos reembolsos efetuados pelos governos federal e estadual a médicos e farmacêuticos que dispensaram medicamentos nos programas de saúde pública. O procurador acusa a Pharmacia 




de manipular estes valores com o objetivo de induzir os médicos a prescrever suas drogas; e de levar o poder público e os consumidores ("inclusive os idosos e os catastroficamente doentes”, escreve ele) a pagar somas “infladas artificialmente" por quimioterapia e outras drogas.

Em entrevista à imprensa, o procurador geral detalhou como age a companhia para incentivar a prescrição da droga Adriamycin, utilizada principalmente para o tratamento do câncer de ovário e de mamas: a Pharmacia fornece ao médico 10 miligramas da droga (aplicada no consultório) por US\$ 7,40. Mas não é este o preço que declara praticar. De fato, com base no preço médio por atacado que a empresa efetivamente declara, o médico é reembolsado pelo programa Medicare em US\$ 34,42; e, sempre com base no preço declarado, recebe ainda do paciente nova-iorquino uma complementação de mais US\$ 8,40, referentes a 20\% do total. Fazendo as contas, o médico "lucra” US\$ 35,62 toda vez que optar por aplicar Adriamycin em vez de uma droga similar, porque recebe US\$ 43,02 por aquilo que a Pharmacia lhe fornece a US\$ 7,40.

Este tipo de desconto não é, em si, ilegal, dentro da legislação norteamericana - se corretamente informado e incorporado ao preço médio declarado pela companhia ao sistema público. A legalidade das práticas é limitada pelo Ato para Proteção dos Pacientes nos Programas Medicare e Medicaid, conhecido como antikickback statute (estatuto contra comissões), editado em 1987 pelo Congresso. De maneira geral, o estatuto penaliza a oferta e o recebimento de quaisquer remunerações que influam sobre a decisão clínica e aumentem os custos dos programas para os governos. Além do Estado de Nova Iorque, também Califórnia, Connecticut, Texas, Minnesota, Nevada perseguem diversas companhias farmacêuticas pela prática de descontos similares. Com as ações, os Estados pretendem obter acordos significativos e permanentes com as companhias que resultem em menor dispêndio com drogas.

\section{A Suprema Corte e o programa do Maine para expandir o acesso}

Em maio de 2003, a Suprema Corte americana decidiu permitir que o Estado do Maine implemente um programa desenhado para estender o acesso a medicamentos com preços subsidiados a todos aqueles residentes não incluídos em sistemas de seguro-saúde públicos ou privados, independentemente de idade ou renda. As autoridades calculam que 325 mil pessoas (a população do Maine é de um milhão e duzentos mil habitantes) serão beneficiados pelo novo programa. Para que ele se torne possível, o estado vai negociar descontos diretamente com as companhias farmacêuticas, constrangendo-as a fornecer drogas a estes não- 
segurados pelo mesmo preço praticado dentro do Medicaid. Medicamentos de companhias que não concordarem em dar descontos nos preços serão incluídos na lista das drogas para as quais se requer pré-autorização para pagamento dentro deste programa. Em geral - autoridades e fabricantes sabem - estas autorizações prévias incentivam a prescrição de drogas alternativas ou de genéricos, o que diminuirá o volume de vendas das companhias que resistirem a baixar os preços.

O Estado pretendia implementar o programa a partir de 2001, o que não foi possível porque o tribunal local, em resposta a ação interposta pela indústria farmacêutica, entendeu ser o programa inconstitucional, além de ferir a legislação do Medicaid. O Estado apelou à corte federal no Maine, e obteve ganho de causa. A discordância entre os tribunais levou o caso à Suprema Corte. Seus juízes, antes de julgarem o caso, perguntaram a opinião da administração Bush sobre o programa do Maine, e ouviram resposta favorável. No julgamento, a questão sobre a inconstitucionalidade foi afastada por 6 votos a 3. Mas o argumento de que a introdução do sistema de pré-autorização possa ferir os interesses de quem faz parte do Medicaid - por estreitar a variedade de medicamentos a que tem acesso - dividiu a Corte, que decidiu então permitir que o Estado implemente provisoriamente o programa.

Outros 29 Estados esperavam a manifestação da Suprema Corte para adotar programas similares, e podem agora implementá-los.

\section{A administração Bush e a avalia custo-benefício}

As autoridades federais encarregadas de definir políticas de pagamento nos programas Medicare e Medicaid passaram a recomendar, notadamente a partir de março de 2003, que a relação custo-benefício de medicamentos e procedimentos médicos seja levada em conta no momento da decisão clínica. Observadores classificam estas recomendações como uma mudança fundamental na forma de atuação da administração. Não se trata de impor controles de preços explícitos, dizem as autoridades, mas em fazer do governo um comprador mais prudente.

Três medidas demonstram a nova disposição do governo norte-americano. Primeira: no mês de março, foi dito a médicos que evitem prescrever uma nova droga para azia, Nexium, tida como idêntica à mais antiga Prilosec. Ambas as drogas são fabricadas pela mesma companhia, a AstraZeneca. Prilosec, além de mais barata, terá sua patente expirada em dezembro, quando poderá ser substituída por genéricos. Segunda: o programa Medicare passou a recusar o pagamento do preço integral pela droga Aranesp, usada para o tratamento de anemia em 
pacientes com câncer. Até dezembro passado, o Medicare pagava US\$ 3.89 por micrograma de Aranesp. Agora, a administração paga somente US\$ 2,37, um corte de 39\%, por considerar que seus efeitos são "quase idênticos" aos obtidos com a droga mais antiga, Procrit, e deve, portanto, ser remunerada nas mesmas bases. Aranesp é fabricada pela Amgem, e Procrit pela Johnson\&Johnson. Terceira: em abril, o governo informou que analisará se o Medicare deve ou não incluir um novo teste para a detecção do câncer de cólon em quem não apresenta sintomas considerando o seu custo. O fabricante do novo teste, uma empresa chamada Enterix, pleiteia que o Medicare pague por ele US\$ 34,00. Atualmente, o teste utilizado no programa custa US\$ 4,54.

\section{Os investigadores de fraudes de Massachusetts}

O mais ativo e agressivo grupo de combate a fraudes no âmbito dos programas públicos de saúde trabalha em Massachusetts. Três dos maiores acordos obtidos em ações impetradas pelo grupo exemplificam outras práticas ilegais de mercado executadas por companhias farmacêuticas. As três investigações relatadas aqui incidiram sobre estratégias para esconder das autoridades descontos praticados nas vendas a clientes preferenciais, e que a lei exige sejam estendidos àquelas ocorridas dentro do Medicare e Medicaid. Através dos acordos - dois deles alcançados em abril de 2003 e outro em 2002 -, três companhias pagaram mais de 1 bilhão e duzentos milhões de dólares ao poder público.

Em 2002, a TAP Pharmaceuticals foi multada criminalmente em 290 milhões de dólares, e pagou ao governo outros 585 milhões como compensação por danos civis, por distribuir amostras grátis do medicamento Lupron, usado para o tratamento de câncer avançado de próstata. A empresa sabia previamente que as amostras fornecidas de graça a médicos e outros prestadores de serviços seriam aplicadas a segurados do Medicare e Medicaid e cobradas dos programas. Desta forma, a TAP Pharmaceuticals influía na prescrição da droga - por assegurar ganhos a quem escolhesse administrá-la, ou recomendar sua administração - e lesava o poder público e os consumidores por não incluir as amostras grátis no cálculo do preço médio do atacado, tornando-o artificialmente mais alto. Para evitar ser excluída de qualquer compra governamental, a empresa também concordou em participar de um Acordo de Integridade Corporativa, através do qual suas contas serão estritamente acompanhadas durante os próximos 7 anos.

Os dois casos de 2003, contra a Bayer e a GlaxoSmithKline, são similares, e envolvem um plano privado de saúde, o maior dos Estados Unidos, com 6 milhões de associados à época das fraudes - Kaiser Permanent Medical Care 
Program. As penalidades impostas à Bayer foram de US\$ 257 milhões; à GlaxoSmithKline, US\$ 88 milhões. Os procuradores denominaram o golpe de lick and stick, lamba e cole. Funcionava assim: a Kaiser, dado o volume de seus associados, comprava o antibiótico Cipro, o anti-hipertensivo Adalat - ambos da Bayer -, o antidepressivo Paxil, e o antialérgico Flonase - da Glaxo -, a preços mais baixos do que aqueles cobrados pelas companhias aos programas Medicare e Medicaid. O Ato de Proteção aos Pacientes, no entanto, obriga as companhias a vender ao governo pelo melhor preço praticado por elas. Para manter o cliente, e ao mesmo tempo não perder dinheiro na relação com o governo, as companhias farmacêuticas forneciam os medicamentos à Kaiser, que os re-rotulava (lick and stick) com outra denominação, e assim fugir à obrigação de relatar os preços menores.

O caso do Cipro ilustra o impacto da concorrência. No interesse da melhor gestão de seus custos e provimento dos serviços de saúde aos associados, a Kaiser (que não visa lucro) decidiu deixar de comprar o antibiótico da Bayer para substitui-lo pelo Floxin, da Johnson\&Johnson, de preço menor. A decisão "desesperou" a Bayer, que naquela altura vendia 7 milhões de dólares em Cipro ao seguro-saúde - inclusive porque as decisões tomadas pela Kaiser eram freqüentemente seguidas por outros seguros. Mas se a Bayer oferecesse vender ao preço cobrado pela Johnson\&Johnson, o novo valor para o Cipro seria menor do que aquele cobrado dos programas públicos, e ela então perderia dezenas de milhões de dólares para manter o cliente. Foi a Kaiser quem sugeriu a solução: a Bayer enviaria o Cipro como usualmente, mas com as palavras "Distribuído pelos Hospitais da Fundação Kaiser” no rótulo, que traria também o código numérico de identificação da Kaiser, e não da Bayer - escapando assim aos controles e à obrigação de reportar o menor preço ao governo.

\section{Os grandes escritórios de advocacia voltam os olhos para a indústria farmacêutica}

Desenvolver medicamentos para condições crônicas e muito generalizadas assegura às companhias farmacêuticas vendas em grande quantidade e por longos períodos de tempo. Por um lado. Mas, por outro, criam nelas uma vulnerabilidade. Nenhum ensaio clínico anterior à comercialização de uma droga dura tanto tempo e envolve tantos voluntários para que todos os efeitos colaterais e adversos de medicamentos usados a longo prazo possam ser previstos. É esta vulnerabilidade que os advogados pretendem explorar de maneira sistemática, depois dos sucessos das ações contra a indústria do tabaco e do amianto. 
O caso do Baycol, medicamento contra colesterol da Bayer, exemplifica esta nova ameaça potencial à indústria. Sessenta escritórios trabalharam em conjunto para buscar compensações da empresa. A empresa retirou o medicamento do mercado em 2001 por ele estar relacionado a 30 mortes. Esperam-se milhares de processos. O primeiro deles, no Texas, terminou com vitória da companhia, que provou ter agido responsavelmente. O Baycol causou, nos pacientes que morreram, uma rara doença muscular chamada rabdomiolise. O revés não parou o trabalho dos escritórios de advocacia, que dividiram as tarefas: parte deles dedica-se a encontrar quem queira acionar a companhia, outros realizam o escrutínio das milhares de páginas de documentos que as companhias são obrigadas a abrir em casos como este, outros escrevem os argumentos...

\section{Reação da indústria farmacêutica}

A associação que fala em nome da indústria e defende seus interesses nos Estados Unidos chama-se PhRMA - Pharmaceutical Research and Manufacturers of America. Dado o desejo dos governos de mudar a legislação dos programas que envolvem compra de medicamentos e a crescente onda de críticas à indústria em razão dos preços praticados, a associação decidiu aumentar seu esforço de convencimento por meio do lobby: o orçamento alocado para esta atividade, dentro e fora dos Estados Unidos, crescerá 23\% de 2003 para 2004. Com 150 milhões de dólares, a PhRMA pretende combater a "demonização" da indústria - palavras deles —, agindo no Legislativo, formando organizações de apoio e pagando economistas para produzir artigos de jornal e monografias que respondam às críticas. 